\title{
BMJ Open Population-based cohort study of warfarin-treated patients with atrial fibrillation: incidence of cardiovascular and bleeding outcomes
}

\author{
Arlene M Gallagher, ${ }^{1,2}$ Tjeerd P van Staa, ${ }^{1,2}$ Tarita Murray-Thomas, ${ }^{1}$ Nils Schoof ${ }^{3}$ \\ Andreas Clemens, ${ }^{4,5}$ Diana Ackermann, ${ }^{3}$ Dorothee B Bartels ${ }^{3,6}$
}

To cite: Gallagher AM, van Staa TP, Murray-Thomas T, et al. Population-based cohort study of warfarintreated patients with atrial fibrillation: incidence of cardiovascular and bleeding outcomes. BMJ Open 2014;4:e003839. doi:10.1136/bmjopen-2013003839

- Prepublication history and additional material for this paper is available online. To view these files please visit the journal online (http://dx.doi.org/10.1136/ bmjopen-2013-003839).

Received 16 August 2013 Revised 10 December 2013 Accepted 12 December 2013

CrossMark

For numbered affiliations see end of article.

Correspondence to Arlene Gallagher: arlene.gallagher@cprd.com

\section{ABSTRACT}

Objectives: Atrial fibrillation (AF) is the most common cardiac rhythm disorder with a significant health burden. The aim of this study was to characterise patients with recently diagnosed $\mathrm{AF}$ and to estimate the rates of comorbidities and outcome events requiring hospitalisation in routine clinical practice.

Design: Pharmacoepidemiological cohort study using observational data.

Methods/setting: This study included 16513 patients with a first diagnosis of AF between 1 January 2005 and 28 February 2010 (newly diagnosed patients) using data from the UK Clinical Practice Research Datalink (CPRD) linked to Hospital Episode Statistics (HES) and the Office for National Statistics mortality data. Exposure was stratified by vitamin $\mathrm{K}$ antagonist (VKA) exposure (non-use, current, recent and past exposure) based on prescriptions and/or international normalised ratio measurements, and followed for outcome events of interest based on diagnosis codes in the databases, that is, vascular outcomes, bleeding events and others. The main focus of the study was on outcome events requiring hospitalisation using the HES data.

Results: The incidence of vascular outcome hospitalisations (myocardial infarction (MI), stroke or systemic arterial peripheral embolism) was $3.8(95 \% \mathrm{Cl}$ 3.5 to 4.0$) / 100$ patient-years. The incidence of stroke was 0.9 (0.8 to 1.1) during current VKA exposure, 2.2 (1.6 to 2.9) for recent, 2.4 (1.9 to 2.9) for past and 3.4 (3.1 to 3.7) during non-use. MI incidence was 0.7 (0.6 to 0.9 ) for current VKA exposure, 0.7 (0.4 to 1.2) for recent, 1.1 (0.8 to 1.5) for past and 1.9 (1.7 to 2.1) during non-use. The incidence of bleeding event hospitalisations was 3.8 (3.4 to 4.2) for current VKA exposure, 4.5 (3.7 to 5.5) for recent, 2.7 (2.2 to 3.3 ) for past and 2.9 (2.6 to 3.2 ) during non-use; $38 \%$ of intracranial bleeds and $6 \%$ of gastrointestinal bleeds were fatal.

Conclusions: This population-based study from recent years provides a comprehensive characterisation of newly diagnosed patients with $\mathrm{AF}$ and incidence estimates of common outcomes with a focus on hospitalised events stratified by VKA exposure. This study will help to place future data on new oral anticoagulants into perspective.

\section{Strength and limitations of this study}

Stratified analysis of current, recent and past exposure, as well as periods of no vitamin $\mathrm{K}$ antagonist (VKA) use, showing substantial differences in comorbidities and outcome events.

- Analysis of only newly diagnosed patients with atrial fibrillation (AF), reducing the risk of bias and reflecting the most current population diagnosed with AF

- Patients were not randomised to a particular treatment.

- Information on the diagnostic criteria used for the diagnosis of $\mathrm{AF}$ is not available in the Clinical Practice Research Datalink database.

- Only crude estimates were estimated which do not allow assessment of causal associations.

\section{INTRODUCTION}

Atrial fibrillation (AF) is the most common cardiac rhythm disorder and represents a significant healthcare burden globally. There are two cornerstones in AF management: thromboprophylaxis and heart rate or heart rhythm control. $^{1}$ The leading anticoagulation treatment options are vitamin $\mathrm{K}$ antagonists (VKAs). The main challenges of treatment with VKAs are close monitoring of the anticoagulant effect (international normalised ratio (INR) measures) to maintain the right anticoagulation level, dietary restrictions to allow for a constant dosing and several drugdrug interactions. Although VKAs are very effective in stroke prevention when optimally dosed, the management challenges present a significant unmet need for other treatment options. ${ }^{2}$ New oral anticoagulants (NOACs) were developed and are available for the prevention of stroke in patients with $\mathrm{AF}$. The reversible direct thrombin inhibitor, dabigatran etexilate, was the first approved NOAC based on the RE-LY trial, and is available in more 
than 90 countries worldwide. ${ }^{3}$ Recently, the factor Xa inhibitors rivaroxaban and apixaban were also approved.

To supplement the data seen in the controlled environment of clinical trials, routine data are important to describe the rates of comorbidities and outcome events in the target population as seen in clinical practice. Such data should originate from the same time frame in which the corresponding clinical trials were conducted, since secular trends including changes in concomitant treatments might influence disease prevalence and incidence. Of particular importance are cardiovascular diseases, which often coexist with $\mathrm{AF}^{4}$ In addition, known side effects of standard treatment such as bleeding are of importance.

The objectives were to describe the characteristics of patients with the first diagnosis of AF between 1 January 2005 and 28 February 2010 (newly diagnosed patients) and to estimate the incidence of cardiovascular and other outcomes, including bleeding events, in patients with $\mathrm{AF}$, overall and in patients being exposed/nonexposed to VKA in the same time frame of the conduct specifically of the RE-LY trial.

\section{METHODS}

\section{Data sources}

This study used the Clinical Practice Research Datalink (CPRD), primary care database (GOLD), the hospital episode statistics (HES) and the Office for National Statistics (ONS) mortality data from the UK.

The CPRD GOLD (formally known as General Practice Research Database (GPRD)) comprises computerised medical records of general practitioners (GPs) from the UK. Patients are affiliated with a practice, which centralises the medical information from the GPs, specialist referrals and hospitalisations. The data recorded include demographic information, prescriptions, clinical events, preventive care, specialist referrals, hospital admissions and their major outcomes. ${ }^{5}$ CPRD GOLD currently includes about $8 \%$ of the UK population. A recent systematic review of all validation studies found that the medical data in CPRD GOLD were generally of high validity; this included an assessment of $\mathrm{AF}$ and myocardial infarction (MI). ${ }^{6}$ Practices contributing to the database are each assigned a date at which they are considered up-to-standard (UTS). The CPRD recommend that analyses are performed on data following the practice UTS date.

The national HES data contain details of all admissions to National Health Service (NHS) hospitals in England. For each hospitalised patient, the hospital charts are reviewed, dates of admission and discharge and main diagnoses are extracted, coded by coding staff and collated nationally into HES. Further details on HES data can be found in the online supplement material. Data are available from April 1997.

The ONS mortality data contain the date and cause of death, from the official death certificate, for the population of England and Wales from January 2001.
HES and ONS data are linked to GOLD data via the NHS number, a unique identifier. The linkage uses a combination of the patient's NHS number, gender and partial date of birth. Not all patients in GOLD are eligible to be linked to these data sources, for example, if they reside in Scotland or they lack a valid NHS identifier. Over $40 \%$ of patients in GOLD have now been linked individually and anonymously to the HES and to the ONS mortality data.

\section{Study population}

Patients were included in the study if their first AF record occurring during the study period (1 January 2005-28 Febuary 2010) was identified in GOLD, where they had at least 1 year of UTS follow-up prior to the first $\mathrm{AF}$ diagnosis(ie, incident patients). The Read codes used for defining AF can be found in online supplementary table S4. No free text or further information was used to identify/validate the diagnosis of AF. The index date was the date of this first $\mathrm{AF}$ record. Patients were excluded if they were aged less than 18 at the index date or if they had a history of heart valve problems/replacement prior. This population was further restricted to those who were eligible for linkage with HES and ONS mortality data (ie, have a valid NHS number and are registered at a practice that was participating in the linkage programme), creating the study population of interest (figure 1). In online supplementary table S5, a comparison between the incident $\mathrm{AF}$ population in CPRD and the incident AF population eligible for linkage can be found. Patients were followed from the index date until the earliest of the respective outcome of interest, transfer out of the practice, last data collection or death, whichever date came first.

The total period of follow-up was analysed for prescriptions for VKA and/or laboratory measurements for INR as a proxy for VKA treatment. The duration of each anticoagulation prescription was taken as 28 days. Patients who received a repeat prescription within 30 days after the expected end of a prescription were assumed to be continuously treated. INR measurements were treated as an indicator for VKA exposure and therefore treated in the same way as prescriptions (ie, assigning 28 days of treatment). The follow-up period for each patient was divided into periods of non-use, current, recent and past exposure:

i Non-use: the time between diagnosis of $\mathrm{AF}$ and the first prescription of an anticoagulant/INR measurement (if they started treatment after diagnosis), or the whole follow-up for the patients who never receive treatment;

ii Current exposure: the period when there is a valid prescription/INR measurement; from the date of the prescription/INR measurement until day 28 after the prescription/INR measurement;

iii Recent exposure: the period between end of treatment and 3 months later; from the day after treatment ends (28 days after the last prescription/INR measurement) to 90 days later; 
iv Past exposure: subsequent follow-up time after recent treatment ( $>90$ days after the end of treatment).

In the outcome analysis, patients could be assigned different exposure status. Throughout the follow-up time, a single patient could provide person-time to one or more periods of non-use, current, recent or past exposure over the course of the study period, that is, the categories of exposure are not mutually exclusive on patient level.

\section{Outcomes of interest}

For each outcome, we identified the first-ever record during follow-up after diagnosis of $\mathrm{AF}$ as defined above. Assessment of the incidence rate of $\mathrm{AF}$ in the general practice setting was not in the scope of this study. Patients who experienced the first-ever outcome prior to the start of follow-up were excluded from the analysis of that outcome (although such patients could be included into the analyses of other outcomes). Four main sets of outcomes were examined: vascular outcomes, bleeding events, hospitalisation due to any cause and due to AF and all-cause mortality. The vascular outcomes recorded as hospital admission in HES were stroke (categorised into haemorrhagic, ischaemic or unspecified stroke), systemic peripheral arterial embolism and MI. Fatal events were those where the date of death from the death certificate was within 10 days of the outcome. Bleedings (from HES) were defined based on a comprehensive list of bleeding codes (96 International classification of Diseases (ICD)-10 codes-see online supplementary table S3) and categorised into intracranial and extracranial. Gastrointestinal (GI) bleeds (based on 23 ICD-10 codes) were analysed as a subgroup of extracranial bleeds. Hospitalisation in general and due to AF was assessed using the primary ICD-10 code I48 from the hospital diagnosis. Finally, all-cause mortality was based on the data from death certificates (from ONS).

\section{Covariables}

Covariables were assessed from before or on index date. A medical history (at any time prior to the index date) of acute MI, stroke, systemic peripheral arterial embolism, vascular event, coronary artery disease $(\mathrm{CAD})$, congestive heart failure (CHF), hypertension, diabetes mellitus and liver and renal impairment was recorded. The baseline $\mathrm{CHADS}_{2}$ and $\mathrm{CHA}_{2} \mathrm{DS}_{2}-\mathrm{VASc}$ were also calculated. ${ }^{78}$ The $\mathrm{CHADS}_{2}$ score is based on a point system, where two points are assigned to a history of stroke or transient ischaemic attack and one point each is assigned for CHF, history of hypertension, age of 75 years or older and diabetes mellitus. ${ }^{7}$ The $\mathrm{CHA}_{2} \mathrm{DS}_{2}$-VASc score extends this scoring system by age 65-74, female sex and history of vascular disease. ${ }^{8} \mathrm{~A}$ recent publication of patients with chronic AF showed that the $\mathrm{CHADS}_{2}$ score is predictive for the risk of stroke in the CPRD database. ${ }^{9}$ Smoking status was calculated from the CPRD records of smoking status and from searching for smoking records in the patient's history using a Read-code list. ${ }^{10}$ Only records from before or on index date were included. Records were categorised into non-smoker, ex-smoker and smoker.

Prescriptions issued during the 3 months before the index date of antiarrhythmics, statins, antiplatelets, anticoagulants, diabetes medication and antihypertensives were also captured. Antihypertensives included ACE inhibitors, angiotensin-II receptor antagonists, $\beta$-adrenoceptor blocking drugs, calcium channel blockers, centrally acting antihypertensive drugs, diuretics with potassium, thiazides and related diuretics.

Deprivation was calculated by linking the postcode of the patient to the Index of Multiple Deprivation (IMD). The IMD combines a number of indicators into a single deprivation score for each small area. The indicators differ between regions in the UK generally, but include income, employment, health and the living environment. The quintiles relate to the country as a whole.

\section{Sensitivity analyses}

Several sensitivity analyses were performed. First, we repeated the analysis of (1) cardiovascular outcomes based on the Read-codes recorded by the GPs, and (2) all bleeding outcomes (intracranial, extracranial, GI) based on the 59 previously published ICD-10 codes. ${ }^{11} 12$ Second, we changed the time window for fatal events from 10 to 30 days, that is, the date of death from the death certificate was within 30 days of the outcome.

\section{Statistical analyses}

Incidence rates per 100 person-years (PY) were estimated and corresponding 95\% CI were calculated assuming a Poisson distribution of events. The denominator for rates calculation was derived as the sum of the PY of follow-up of patients during the study period. Person-time for treatment periods consisted of the sum of follow-up accrued on the index date and during probable use of anticoagulation treatment. Use of anticoagulation treatment was defined as the period during prescribing of anticoagulation therapy and/or laboratory measurements for INR. Follow-up was censored at the earliest of the outcome of interest, transfer out of the practice, last data collection or death. Person-time for untreated periods consisted of the sum of follow-up from the index date until the earliest of the start of a treatment of interest (minus 1 day), the outcome of interest, transfer out of the practice, last data collection or death.

All analyses have been performed with Stata version 11.2.

\section{RESULTS}

A total of 48121 patients were identified with a first AF record during UTS follow-up and within the study period. Figure 1 describes how patients were subsequently excluded from the study cohort. The overall cohort of incident AF patients included 42008 patients, of whom 25495 were excluded for not being eligible for linkage to the HES or ONS data sources. A total of 


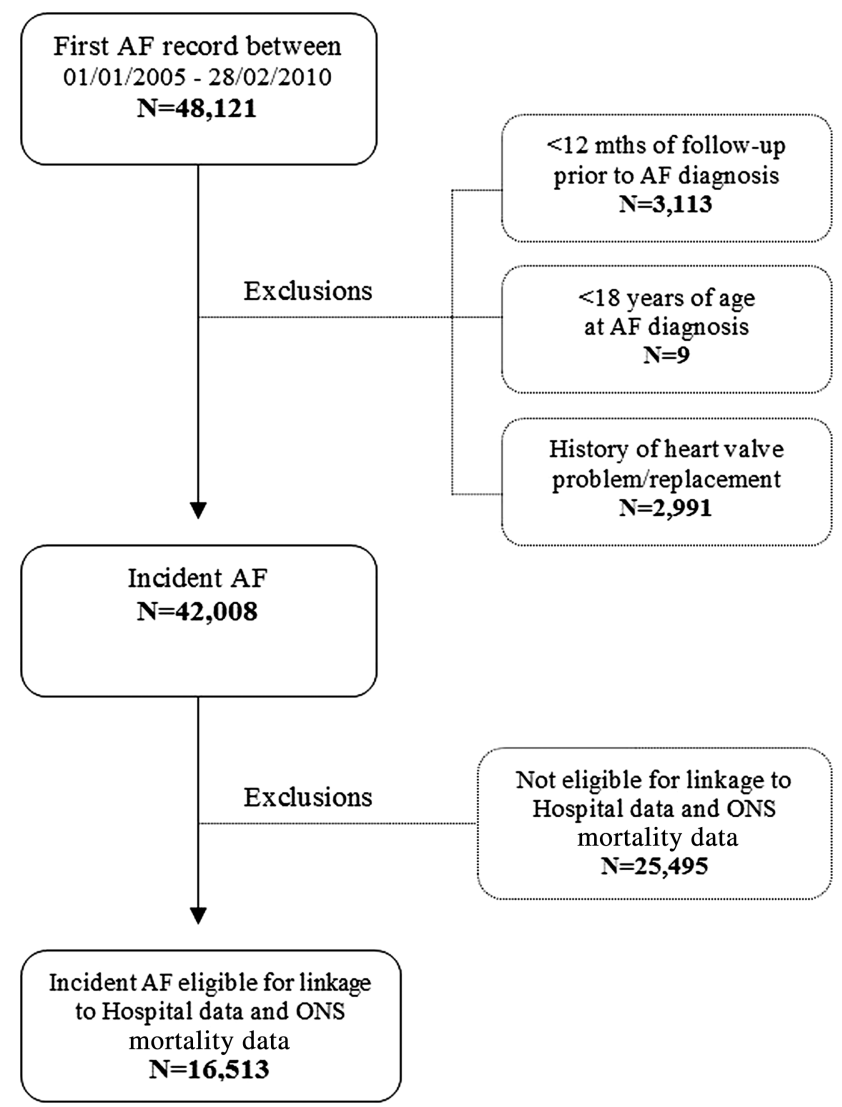

Figure 1 Consort diagram showing the composition of the study population-Incident atrial fibrillation Cohort. AF, atrial fibrillation; ONS, Office of National Statistics.

16513 patients were eligible for linkage to HES and ONS mortality data and were the main subject of this study. There were no major differences in patient characteristics between the overall cohort of incident AF patients $(\mathrm{N}=42008)$ and the final study population $(\mathrm{N}=16$ 513) (see online supplementary table S5), other than a shorter follow-up in the study population: the median (range) duration of follow-up in the overall cohort was $2.2(0-6)$ vs $1.7(0-5)$ years in the final linked AF cohort.

Table 1 shows the baseline characteristics for the study population. The mean age (SD) was 77 (11) for female patients and 72 (12) for male patients; $48 \%$ of the patients were women. Defining the risk of stroke based on $\mathrm{CHADS}_{2}$ score resulted in $21 \%$ being at low risk $\left(\mathrm{CHADS}_{2}\right.$ score of 0$), 61 \%$ at moderate risk $\left(\mathrm{CHADS}_{2}\right.$ score of 1 or 2$)$ and $18 \%$ at high risk $\left(\mathrm{CHADS}_{2}\right.$ score of greater than 2$)$.

Overall, 1151 vascular events (136 fatal events and 1015 non-fatal events) were recorded (table 2). There were 716 strokes (94 fatal), 68 systemic peripheral arterial embolisms (4 fatal) and 403 MIs (43 fatal). The overall incidence of vascular outcomes was 3.8 (95\% CI 3.5 to 4.0) per $100 \mathrm{PY}$, and was 1.8 (95\% CI 1.6 to 2.1$)$ during current exposure, 3.1 (2.4 to 3.9 ) for recent, 3.5 (2.9 to 4.2) for past exposure and 5.5 (5.1 to 5.9) during non-use. The overall incidence of stroke was 2.3 (2.1 to
2.5), and 0.9 (0.8 to 1.1) during current exposure, 2.2 (1.6 to 2.9) for recent, 2.4 (1.9 to 2.9) for past exposure and 3.4 (3.1 to 3.7) during non-use. The overall incidence of MI was 1.3 (1.2 to 1.4 ) and was higher during past-use and non-use compared to current and recent exposure $(1.1,1.9$ vs $0.7,0.7)$. Systemic peripheral arterial embolisms were few $(0.2 / 100 \mathrm{PY})$. Owing to the low number of fatal events, there was no clear trend with VKA exposure and the incidences of any fatal vascular event or incidences of a fatal stroke, MI or systemic peripheral arterial embolism.

Bleeding events occurred with an incidence of 3.3 (3.1 to 3.5) (table 3). The incidence rate during current exposure was 3.8 (3.4 to 4.2 ); and 4.5 (3.7 to 5.5) for recent, whereas non-use and past exposure to VKA resulted in similar incidences (2.9 (2.6 to 3.2) and 2.7 (2.2 to 3.3$))$. Twelve per cent $(n=120)$ were intracranial bleeds and overall nearly $38 \%$ of them were fatal; $50 \%$ were fatal during current exposure. More than one-third of the extracranial bleeds were GI bleeds $(n=334), 6 \%$ of them were fatal; during current exposure $4 \%$ were fatal. GI bleed events occurred similarly frequently during current/recent and past/non-use of VKAs.

The incidences of hospitalisation for any cause, hospitalisation for AF and all-cause mortality are displayed in table 4 . Overall, $71 \%$ of the patients were hospitalised with an incidence of 88.0 (86.4 to 89.6$) / 100$ personyears for any hospitalisation and 16.0 (15.5 to 16.5) for hospitalisation due to AF.

All-cause mortality was 8.9 (8.6 to 9.3$) / 100$ personyears overall and was highest during recent VKA exposure and lowest during current exposure (15.3 and 3.4, respectively).

The sensitivity analysis for the cardiovascular events based on diagnosis recorded by the GP showed slightly higher incidences than those based on hospital data for MI and stroke, and slightly lower incidences for systemic peripheral arterial embolism (see online supplementary table S1). Bleeding events defined by previously published ICD codes lead to lower bleeding incidences (overall 2.5 (2.3 to 2.7)) and smaller differences between current (3.0 (2.6 to 3.3)) and recent exposure (3.4 (2.7 to 4.3)) (see online supplementary table S2). Changing the time window for fatal events from 10 to 30 days between the outcome of interest and the death certificate date did not change the results substantially (data not shown).

\section{DISCUSSION}

This study presents a detailed picture of the prevalence and incidence of common comorbidities and outcome events in a large cohort of newly diagnosed patients with AF shortly prior to launch of new NOACs. Moreover, VKA use was stratified into current, recent, past exposure and periods of non-use, showing substantial differences between those exposure groups. Another hallmark of this study is that only newly diagnosed patients were included instead of a mixture of incident and prevalent 
Table 1 Description of the study population, UK 2005-2010

\begin{tabular}{|c|c|c|c|}
\hline Characteristics & $\begin{array}{l}\text { Female } \\
\mathrm{N}=7921\end{array}$ & $\begin{array}{l}\text { Male } \\
\mathrm{N}=8592\end{array}$ & $\begin{array}{l}\text { Total } \\
\mathrm{N}=16513\end{array}$ \\
\hline Length of follow-up (years): mean (SD) & $1.9(1.4)$ & $2.0(1.4)$ & $1.9(1.4)$ \\
\hline Length of follow-up (years): median (range) & $1.7(0-5)$ & $1.8(0-5)$ & $1.7(0-5)$ \\
\hline Age: mean (SD) & 77 (11.2) & $72(12.2)$ & $74(12.0)$ \\
\hline Age: median (range) & $79(25-107)$ & $73(21-101)$ & $76(21-107)$ \\
\hline Gender: female & $7921(100.0 \%)$ & - & $7921(48.0 \%)$ \\
\hline BMI: mean (SD) & $27(6)$ & $28(5)$ & $28(6)$ \\
\hline BMI: median (range) & $26(12-69)$ & $27(12-70)$ & $27(12-70)$ \\
\hline Smoker & $776(9.8 \%)$ & $1227(14.3 \%)$ & 2003 (12.1\%) \\
\hline Drinker & $4858(61.3 \%)$ & $6743(78.5 \%)$ & $11601(70.3 \%)$ \\
\hline \multicolumn{4}{|l|}{ Deprivation index of patient's home } \\
\hline 0 (least deprived) & $1251(15.8 \%)$ & $1502(17.5 \%)$ & $2753(16.7 \%)$ \\
\hline 1 & $1388(17.5 \%)$ & $1508(17.6 \%)$ & $2896(17.5 \%)$ \\
\hline 2 & 1259 (15.9\%) & $1376(16.0 \%)$ & 2635 (16.0\%) \\
\hline 3 & $1219(15.4 \%)$ & $1232(14.3 \%)$ & $2451(14.8 \%)$ \\
\hline 4 (most deprived) & 1144 (14.4\%) & $1082(12.6 \%)$ & 2226 (13.5\%) \\
\hline Patient deprivation: unknown & $1660(21.0 \%)$ & $1892(22.0 \%)$ & $3552(21.5 \%)$ \\
\hline CHADS2 risk score: mean (SD) & $1.64(1.15)$ & $1.37(1.20)$ & $1.50(1.18)$ \\
\hline CHADS2 risk score: median (IQR) & $2(1-2)$ & $1(0-2)$ & $1(1-2)$ \\
\hline 0 & $1215(15.3 \%)$ & $2278(26.5 \%)$ & $3493(21.2 \%)$ \\
\hline 1 & $2633(33.2 \%)$ & $2875(33.5 \%)$ & $5508(33.4 \%)$ \\
\hline 2 & $2574(32.5 \%)$ & $2031(23.6 \%)$ & $4605(27.9 \%)$ \\
\hline 3 & $897(11.3 \%)$ & $881(10.3 \%)$ & $1778(10.8 \%)$ \\
\hline 4 & $463(5.8 \%)$ & $383(4.5 \%)$ & $846(5.1 \%)$ \\
\hline 5 & $131(1.7 \%)$ & $129(1.5 \%)$ & $260(1.6 \%)$ \\
\hline 6 & $8(0.1 \%)$ & $15(0.2 \%)$ & $23(0.1 \%)$ \\
\hline CHA2DS2-VASc risk score: mean (SD) & $3.74(1.57)$ & $2.40(1.7)$ & $3.04(1.77)$ \\
\hline CHA2DS2-VASc risk score: median (IQR) & $4(3-4)$ & $2(1-3)$ & $3(2-4)$ \\
\hline 0 & $0(0.0 \%)$ & $1258(14.6 \%)$ & $1258(7.6 \%)$ \\
\hline 1 & $569(7.2 \%)$ & $1405(16.4 \%)$ & $1974(12.0 \%)$ \\
\hline 2 & $900(11.4 \%)$ & $2199(25.6 \%)$ & $3099(18.8 \%)$ \\
\hline 3 & $2219(28.0 \%)$ & $1830(21.3 \%)$ & $4049(24.5 \%)$ \\
\hline 4 & 2369 (29.9\%) & $865(10.1 \%)$ & $3234(19.6 \%)$ \\
\hline 5 & $788(9.9 \%)$ & $502(5.8 \%)$ & $1290(7.8 \%)$ \\
\hline 6 & $481(6.1 \%)$ & $380(4.4 \%)$ & $861(5.2 \%)$ \\
\hline 7 & $451(5.7 \%)$ & $136(1.6 \%)$ & $587(3.6 \%)$ \\
\hline 8 & $136(1.7 \%)$ & $17(0.2 \%)$ & $153(0.9 \%)$ \\
\hline 9 & $8(0.1 \%)$ & $0(0.0 \%)$ & $8(<0.1 \%)$ \\
\hline \multicolumn{4}{|l|}{ History of* } \\
\hline Acute myocardial infarction & $515(6.5 \%)$ & $1106(12.9 \%)$ & $1621(9.8 \%)$ \\
\hline Stroke & $884(11.2 \%)$ & $960(11.2 \%)$ & $1844(11.2 \%)$ \\
\hline Systemic peripheral arterial embolism & $28(0.4 \%)$ & $21(0.2 \%)$ & $49(0.3 \%)$ \\
\hline Vascular event & $1349(17.0 \%)$ & $1924(22.4 \%)$ & $3273(19.8 \%)$ \\
\hline CAD & $1021(12.9 \%)$ & $1755(20.4 \%)$ & $2776(16.8 \%)$ \\
\hline $\mathrm{CHF}$ & $659(8.3 \%)$ & $698(8.1 \%)$ & $1357(8.2 \%)$ \\
\hline Hypertension & $4280(54.0 \%)$ & $3833(44.6 \%)$ & $8113(49.1 \%)$ \\
\hline Diabetes & 1098 (13.9\%) & $1428(16.6 \%)$ & $2526(15.3 \%)$ \\
\hline Liver impairment & $133(1.7 \%)$ & $204(2.4 \%)$ & $337(2.0 \%)$ \\
\hline Renal impairment & $1342(16.9 \%)$ & $1171(13.6 \%)$ & $2513(15.2 \%)$ \\
\hline \multicolumn{4}{|l|}{ Treatment with $\dagger$} \\
\hline Antiarrhythmics & $716(9.0 \%)$ & $706(8.2 \%)$ & $1422(8.6 \%)$ \\
\hline Statins & $2435(30.7 \%)$ & $3287(38.3 \%)$ & $5722(34.7 \%)$ \\
\hline Antiplatelets & 3856 (48.7\%) & $4292(50.0 \%)$ & $8148(49.3 \%)$ \\
\hline Aspirin & $3570(45.1 \%)$ & 4029 (46.9\%) & 7599 (46.0\%) \\
\hline Low dose aspirin (<100 mg) & $3460(43.7 \%)$ & $3871(45.1 \%)$ & $7331(44.4 \%)$ \\
\hline High dose aspirin (>=100 mg) & $155(2.0 \%)$ & $191(2.2 \%)$ & $346(2.1 \%)$ \\
\hline Clopidogrel & $387(4.9 \%)$ & $429(5.0 \%)$ & $816(4.9 \%)$ \\
\hline Other antiplatelets & $130(1.6 \%)$ & $179(2.1 \%)$ & $309(1.9 \%)$ \\
\hline
\end{tabular}




\begin{tabular}{|c|c|c|c|}
\hline Characteristics & $\begin{array}{l}\text { Female } \\
\mathrm{N}=7921\end{array}$ & $\begin{array}{l}\text { Male } \\
\mathrm{N}=8592\end{array}$ & $\begin{array}{l}\text { Total } \\
\mathrm{N}=16513\end{array}$ \\
\hline Anticoagulants & $762(9.6 \%)$ & $1054(12.3 \%)$ & $1816(11.0 \%)$ \\
\hline Antidiabetics & $636(8.0 \%)$ & $862(10.0 \%)$ & $1498(9.1 \%)$ \\
\hline Oral antidiabetics & $548(6.9 \%)$ & $753(8.8 \%)$ & $1301(7.9 \%)$ \\
\hline Insulin & $158(2.0 \%)$ & 207 (2.4\%) & $365(2.2 \%)$ \\
\hline Other injectable antidiabetics & $0(0.0 \%)$ & $2(<0.1 \%)$ & $2(<0.1 \%)$ \\
\hline Antihypertensives $\ddagger$ & $5361(67.7 \%)$ & $5386(62.7 \%)$ & $10747(65.1 \%)$ \\
\hline
\end{tabular}

patients reducing the potential for bias and reflecting the most current population diagnosed with AF.

Vascular event rates were lowest during current VKA exposure and showed increasing rates during recent and past exposure, with the highest incidence during non-use, particularly observed for ischaemic stroke. Previously reported incidence rates of stroke are in the same range as in our study but did not include detailed information on VKA use from newly diagnosed patients with $\mathrm{AF}$ of the recent years. ${ }^{13}{ }^{14}$ For ischaemic stroke, the incidence rate reported by Go et $a l^{15}$ in patients taking warfarin and for patients not taking warfarin is in agreement with our study. For MI, the incidence rate was comparable between current and recent VKA use, whereas past and non-use showed a trend to higher incidence in this study. It has been reported that patients with $\mathrm{AF}$ are at higher risk for coronary events. ${ }^{16}$ Sensitivity analysis for cardiovascular events based on diagnosis recorded by the GP showed a similar trend with regard to the incidences stratified by periods of VKA use, but resulted in slightly higher incidences than those based on hospital data for MI and stroke. This might be explained as the analysis of GP records is more likely to include records of patients for non-hospitalised events, and MIs leading to death without hospitalisation.

The incidence of bleeding events in this study was comparable during current and recent VKA use, whereas lower incidences were shown during past and non-use, which might be explained by the nature of VKA treatment. Go et $a l^{15}$ reports incidence rates of intracranial haemorrhage based on hospitalisations of 0.5 (95\% CI 0.4 to 0.6$)$ and $0.2(0.2$ to 0.3$) / 100$ person-years (PY) among patients taking and not taking warfarin. This compares to 0.4 (0.3 to 0.5$)$ and 0.6 (0.4 to 1.1$) / 100 \mathrm{PY}$ during current and recent exposure, and 0.2 (0.1 to 0.4 ) and $0.4(0.3$ to 0.5$) / 100 \mathrm{PY}$ for past and non-use in this study, respectively. The similar intracranial bleeding incidence during non-VKA use compared to current exposure might be explained by contraindications associated with higher risk for intracranial bleedings. For GI bleedings, Go et $a l^{15}$ did not find differences between patients taking and not taking warfarin; this study showed a trend towards higher incidences during recent VKA exposure compared to current exposure, 1.0 (0.7 to 1.4) for past and 1.1 (1.0 to 1.3) /100 PY for non-use. Thus, the bleeding incidence results of our study indicate a potentially increased risk for patients with $\mathrm{AF}$ that recently stopped VKA treatment compared to periods of past exposure and non-use. However, these findings could be related to a general worsening of health status or to the fact that these patients acquired additional bleeding risk factors (eg, start of aspirin use), which lead to stopping of VKA treatment. We used a comprehensive list of 96 ICD-10 codes (see online supplementary table S3) to define bleeding events including additional sites (eg, kidney, uterus, etc). Compared to the code lists published by Hansen and Olesen, which we used for sensitivity analyses, the bleeding rates in our main analysis were higher than the rates observed in the sensitivity analyses (see online supplementary table S2). ${ }^{11}{ }^{12}$ However, the rates in our sensitivity analyses correspond well to the published data. ${ }^{11}$ The proportion of fatal bleeding events was highest among patients suffering from intracranial bleedings (38\% overall, compared to $3 \%$ among extracranial and $6 \%$ among GI bleedings). The proportion of fatal intracranial bleeding events was higher among current $(50 \%)$, recent $(40 \%)$ and past $(63 \%)$ VKA exposure compared to non-use (22\%); however, the number of recent and past exposures was small. This is in line with the ATRIA cohort study conducted between 1996 and 1997, which reported that the risk of death within 30 days after hospitalisation for warfarin-associated intracranial bleedings was $48.6 \% .{ }^{17}$ However, there was no stratification on VKA exposure or on bleeding site. While in this study, any-cause hospitalisation was lowest during current VKA use, there was no clear pattern for AF-hospitalisations dependent on VKA treatment with lowest incidences during past VKA exposure. Mortality was substantially lower during current VKA exposure compared to other exposure periods. This might be related to the protective effect of VKAs for stroke and to the healthy user effect, that is, patients currently taking VKAs might be more adherent to medication and more health conscious. 


\begin{tabular}{|c|c|c|c|c|c|c|c|c|c|c|c|c|c|c|c|}
\hline \multirow[b]{2}{*}{ Event } & \multicolumn{3}{|l|}{ Overall } & \multicolumn{3}{|c|}{ Current exposure } & \multicolumn{3}{|c|}{ Recent exposure } & \multicolumn{3}{|c|}{ Past exposure } & \multicolumn{3}{|l|}{ No use } \\
\hline & $\begin{array}{l}\text { Number of } \\
\text { outcome } \\
\text { events }\end{array}$ & PY & $\begin{array}{l}\text { Incidence* } \\
(95 \% \mathrm{Cl})\end{array}$ & $\begin{array}{l}\text { Number of } \\
\text { outcome } \\
\text { events }\end{array}$ & PY & $\begin{array}{l}\text { Incidence* } \\
(95 \% \mathrm{Cl})\end{array}$ & $\begin{array}{l}\text { Number of } \\
\text { outcome } \\
\text { events }\end{array}$ & PY & $\begin{array}{l}\text { Incidence* } \\
(95 \% \mathrm{Cl})\end{array}$ & $\begin{array}{l}\text { Number of } \\
\text { outcome } \\
\text { events }\end{array}$ & PY & $\begin{array}{l}\text { Incidence }{ }^{*} \\
(95 \% \mathrm{Cl})\end{array}$ & $\begin{array}{l}\text { Number of } \\
\text { outcome } \\
\text { events }\end{array}$ & PY & $\begin{array}{l}\text { Incidence* } \\
(95 \% \mathrm{Cl})\end{array}$ \\
\hline Vascular & 1151 & 30622 & 3.8 (3.5 to 4.0$)$ & 205 & 11137 & $1.8(1.6$ to 2.1$)$ & 69 & 2243 & 3.1 (2.4 to 3.9 ) & 128 & 3644 & 3.5 (2.9 to 4.2$)$ & 749 & 13599 & 5.5 (5.1 to 5.9$)$ \\
\hline Fatal vascular & 136 & 30622 & $0.4(0.4$ to 0.5$)$ & 28 & 11137 & $0.3(0.2$ to 0.4$)$ & 16 & 2243 & 0.7 (0.4 to 1.2$)$ & 23 & 3644 & $0.6(0.4$ to 0.9$)$ & 69 & 13599 & 0.5 (0.4 to 0.6$)$ \\
\hline Non-fatal vascular & 1015 & 30622 & 3.3 (3.1 to 3.5 ) & 177 & 11137 & $1.6(1.4$ to 1.8$)$ & 53 & 2243 & 2.4 (1.8 to 3.1$)$ & 105 & 3644 & 2.9 (2.4 to 3.5$)$ & 680 & 13599 & $5.0(4.6$ to 5.4$)$ \\
\hline MI & 403 & 31421 & $1.3(1.2$ to 1.4$)$ & 83 & 11496 & 0.7 (0.6 to 0.9$)$ & 17 & 2317 & 0.7 (0.4 to 1.2$)$ & 41 & 3749 & $1.1(0.8$ to 1.5$)$ & 262 & 13859 & $1.9(1.7$ to 2.1$)$ \\
\hline Fatal MI & 43 & 31421 & 0.1 (0.1 to 0.2$)$ & 6 & 11496 & $\dagger$ & 5 & 2317 & $0.2(0.1$ to 0.5$)$ & 8 & 3749 & $0.2(0.1$ to 0.4$)$ & 24 & 13859 & $0.2(0.1$ to 0.3$)$ \\
\hline Non-fatal MI & 360 & 31421 & 1.1 (1.0 to 1.3 ) & 77 & 11496 & 0.7 (0.5 to 0.8 ) & 12 & 2317 & 0.5 (0.3 to 0.9$)$ & 33 & 3749 & 0.9 (0.6 to 1.2$)$ & 238 & 13859 & $1.7(1.5$ to 1.9$)$ \\
\hline Stroke & 716 & 31189 & 2.3 (2.1 to 2.5$)$ & 107 & 11340 & $0.9(0.8$ to 1.1$)$ & 50 & 2291 & $2.2(1.6$ to 2.9$)$ & 88 & 3725 & 2.4 (1.9 to 2.9$)$ & 471 & 13833 & 3.4 (3.1 to 3.7 ) \\
\hline Haemorrhagic & 66 & 31888 & $0.2(0.2$ to 0.3$)$ & 23 & 11658 & $0.2(0.1$ to 0.3$)$ & 10 & 2356 & $0.4(0.2$ to 0.8$)$ & 4 & 3821 & $t$ & 29 & 14054 & $0.2(0.1$ to 0.3$)$ \\
\hline Ischaemic & 469 & 31441 & 1.5 (1.4 to 1.6$)$ & 56 & 11440 & 0.5 (0.4 to 0.6$)$ & 29 & 2309 & $1.3(0.8$ to 1.8$)$ & 59 & 3760 & $1.6(1.2$ to 2.0$)$ & 325 & 13932 & 2.3 (2.1 to 2.6$)$ \\
\hline Unspecified & 181 & 31738 & $0.6(0.5$ to 0.7$)$ & 28 & 11569 & $0.2(0.2$ to 0.3$)$ & 11 & 2344 & 0.5 (0.2 to 0.8$)$ & 25 & 3804 & $0.7(0.4$ to 1.0$)$ & 117 & 14020 & $0.8(0.7$ to 1.0$)$ \\
\hline Fatal stroke & 94 & 31189 & $0.3(0.2$ to 0.4$)$ & 21 & 11340 & $0.2(0.1$ to 0.3$)$ & 12 & 2291 & 0.5 (0.3 to 0.9$)$ & 16 & 3725 & $0.4(0.2$ to 0.7$)$ & 45 & 13833 & $0.3(0.2$ to 0.4$)$ \\
\hline Haemorrhagic & 27 & 31888 & $0.1(0.1$ to 0.1$)$ & 12 & 11658 & 0.1 (0.1 to 0.2$)$ & 5 & 2356 & $0.2(0.1$ to 0.5$)$ & 3 & 3821 & $t$ & 7 & 14054 & $t$ \\
\hline Ischaemic & 44 & 31441 & 0.1 (0.1 to 0.2 ) & 7 & 11440 & $\dagger$ & 4 & 2309 & t & 7 & 3760 & $0.2(0.1$ to 0.4$)$ & 26 & 13932 & $0.2(0.1$ to 0.3$)$ \\
\hline Unspecified & 23 & 31738 & $0.1(<0.1$ to 0.1$)$ & 2 & 11569 & $\dagger$ & 3 & 2344 & $t$ & 6 & 3804 & $0.2(0.1$ to 0.3$)$ & 12 & 14020 & $0.1(<0.1$ to 0.1$)$ \\
\hline Non-fatal stroke & 622 & 31189 & 2.0 (1.8 to 2.2 ) & 86 & 11340 & 0.8 (0.6 to 0.9 ) & 38 & 2291 & $1.7(1.2$ to 2.3$)$ & 72 & 3725 & $1.9(1.5$ to 2.4$)$ & 426 & 13833 & 3.1 (2.8 to 3.4$)$ \\
\hline Haemorrhagic & 39 & 31888 & 0.1 (0.1 to 0.2$)$ & 11 & 11658 & $0.1(<0.1$ to 0.2$)$ & 5 & 2356 & $0.2(0.1$ to 0.5$)$ & 1 & 3821 & t & 22 & 14054 & $0.2(0.1$ to 0.2$)$ \\
\hline Ischaemic & 425 & 31441 & $1.4(1.2$ to 1.5$)$ & 49 & 11440 & 0.4 (0.3 to 0.6$)$ & 25 & 2309 & $1.0(0.7$ to 1.6$)$ & 52 & 3760 & $1.4(1.0$ to 1.8$)$ & 299 & 13932 & 2.1 (1.9 to 2.4 ) \\
\hline Unspecified & 158 & 31738 & 0.5 (0.4 to 0.6$)$ & 26 & 11569 & $0.2(0.1$ to 0.3$)$ & 8 & 2344 & 0.3 (0.1 to 0.7 ) & 19 & 3804 & 0.5 (0.3 to 0.8$)$ & 105 & 14020 & $0.7(0.6$ to 0.9$)$ \\
\hline SPAE & 68 & 31855 & $0.2(0.2$ to 0.3$)$ & 21 & 11617 & $0.2(0.1$ to 0.3$)$ & 6 & 2351 & 0.3 (0.1 to 0.6$)$ & 6 & 3823 & $0.2(0.1$ to 0.3$)$ & 35 & 14063 & $0.2(0.2$ to 0.3$)$ \\
\hline Fatal SPAE & 4 & 31855 & t & 3 & 11617 & $\dagger$ & 1 & 2351 & $\dagger$ & 0 & 3823 & t & 0 & 14063 & t \\
\hline Non-fatal SPAE & 64 & 31855 & $0.2(0.2$ to 0.3$)$ & 18 & 11617 & $0.2(0.1$ to 0.2$)$ & 5 & 2351 & 0.2 (0.1 to 0.5$)$ & 6 & 3823 & $0.2(0.1$ to 0.3$)$ & 35 & 14063 & $0.2(0.2$ to 0.3$)$ \\
\hline
\end{tabular}

${ }^{*}$ Number of cases per $100 \mathrm{PY}$

†Not enough events to calculate.

AF, atrial fibrillation; MI, myocardial infraction; SPAE: systemic pulmonary arterial embolism; PY, person-years; VKA, vitamin K antagonist. 
Table 3 Incidence of bleeding outcomes overall and in relation to VKA use for the cohort of patients with AF eligible for linkage, $n=16513$

\begin{tabular}{|c|c|c|c|c|c|c|c|c|c|c|c|c|c|c|c|}
\hline \multirow[b]{2}{*}{ Event } & \multicolumn{3}{|l|}{ Overall } & \multicolumn{3}{|c|}{ Current exposure } & \multicolumn{3}{|c|}{ Recent exposure } & \multicolumn{3}{|c|}{ Past exposure } & \multicolumn{3}{|l|}{ No use } \\
\hline & $\begin{array}{l}\text { Number of } \\
\text { outcome } \\
\text { events }\end{array}$ & PY & $\begin{array}{l}\text { Incidence* } \\
(95 \% \mathrm{Cl})\end{array}$ & $\begin{array}{l}\text { Number of } \\
\text { outcome } \\
\text { events }\end{array}$ & PY & $\begin{array}{l}\text { Incidence* } \\
(95 \% \mathrm{Cl})\end{array}$ & $\begin{array}{l}\text { Number of } \\
\text { outcome } \\
\text { events }\end{array}$ & PY & $\begin{array}{l}\text { Incidence* } \\
(95 \% \mathrm{Cl})\end{array}$ & $\begin{array}{l}\text { Number of } \\
\text { outcome } \\
\text { events }\end{array}$ & PY & $\begin{array}{l}\text { Incidence* } \\
(95 \% \mathrm{Cl})\end{array}$ & $\begin{array}{l}\text { Number of } \\
\text { outcome } \\
\text { events }\end{array}$ & PY & $\begin{array}{l}\text { Incidence }{ }^{*} \\
(95 \% \mathrm{Cl})\end{array}$ \\
\hline All bleed & 1023 & 30693 & 3.3 (3.1 to 3.5 ) & 426 & 11236 & 3.8 (3.4 to 4.2 ) & 101 & 2238 & 4.5 (3.7 to 5.5$)$ & 97 & 3573 & 2.7 (2.2 to 3.3$)$ & 399 & 13645 & 2.9 (2.6 to 3.2 ) \\
\hline Intracranial bleed & 120 & 31854 & $0.4(0.3$ to 0.5$)$ & 46 & 11654 & $0.4(0.3$ to 0.5$)$ & 15 & 2353 & $0.6(0.4$ to 1.1$)$ & 8 & 3811 & $0.2(0.1$ to 0.4$)$ & 51 & 14036 & $0.4(0.3$ to 0.5$)$ \\
\hline Extracranial bleed & 903 & 30778 & 2.9 (2.7 to 3.1$)$ & 380 & 11246 & 3.4 (3.0 to 3.7$)$ & 86 & 2245 & 3.8 (3.1 to 4.7$)$ & 89 & 3593 & 2.5 (2.0 to 3.0$)$ & 348 & 13695 & 2.5 (2.3 to 2.8$)$ \\
\hline Gl bleed & 334 & 31545 & $1.1(0.9$ to 1.2$)$ & 104 & 11560 & $0.9(0.7$ to 1.1$)$ & 35 & 2330 & $1.5(1.0$ to 2.1$)$ & 38 & 3733 & $1.0(0.7$ to 1.4$)$ & 157 & 13921 & $1.1(1.0$ to 1.3$)$ \\
\hline Fatal bleed & 74 & 30693 & $0.2(0.2$ to 0.3$)$ & 33 & 11236 & $0.3(0.2$ to 0.4$)$ & 10 & 2238 & $0.4(0.2$ to 0.8$)$ & 7 & 3573 & $0.2(0.1$ to 0.4$)$ & 24 & 13645 & $0.2(0.1$ to 0.3$)$ \\
\hline Intracranial bleed & 45 & 31854 & 0.1 (0.1 to 0.2$)$ & 23 & 11654 & $0.2(0.1$ to 0.3$)$ & 6 & 2353 & $0.3(0.1$ to 0.6$)$ & 5 & 3811 & $0.1(<0.1$ to 0.3$)$ & 11 & 14036 & $0.1(<0.1$ to 0.1$)$ \\
\hline Extracranial bleed & 29 & 30778 & 0.1 (0.1 to 0.1$)$ & 10 & 11246 & $0.1(<0.1$ to 0.2$)$ & 4 & 2245 & $0.2(<0.1$ to 0.5$)$ & 2 & 3593 & $0.1(<0.1$ to 0.2$)$ & 13 & 13695 & 0.1 (0.1 to 0.2$)$ \\
\hline Gl bleed & 20 & 31545 & $0.1(<0.1$ to 0.1$)$ & 4 & 11560 & $0.0(<0.1$ to 0.1$)$ & 3 & 2330 & $0.1(<0.1$ to 0.4$)$ & 2 & 3733 & $0.1(<0.1$ to 0.2$)$ & 11 & 13921 & $0.1(<0.1$ to 0.1$)$ \\
\hline Non-fatal bleed & 949 & 30693 & 3.1 (2.9 to 3.3 ) & 393 & 11236 & 3.5 (3.2 to 3.9 ) & 91 & 2238 & 4.1 (3.3 to 5.0 ) & 90 & 3573 & 2.5 (2.0 to 3.1 ) & 375 & 13645 & 2.7 (2.5 to 3.0 ) \\
\hline Intracranial bleed & 75 & 31854 & $0.2(0.2$ to 0.3$)$ & 23 & 11654 & $0.2(0.1$ to 0.3$)$ & 9 & 2353 & $0.4(0.2$ to 0.7$)$ & 3 & 3811 & $0.1(<0.1$ to 0.2$)$ & 40 & 14036 & $0.3(0.2$ to 0.4$)$ \\
\hline Extracranial bleed & 874 & 30778 & 2.8 (2.7 to 3.0$)$ & 370 & 11246 & 3.3 (3.0 to 3.6 ) & 82 & 2245 & 3.7 (2.9 to 4.5$)$ & 87 & 3593 & 2.4 (1.9 to 3.0$)$ & 335 & 13695 & 2.4 (2.2 to 2.7$)$ \\
\hline Gl bleed & 314 & 31545 & $1.0(0.9$ to 1.1$)$ & 100 & 11560 & $0.9(0.7$ to 1.1$)$ & 32 & 2330 & $1.4(0.9$ to 1.9$)$ & 36 & 3733 & $1.0(0.7$ to 1.3$)$ & 146 & 13921 & $1.0(0.9$ to 1.2$)$ \\
\hline
\end{tabular}

${ }^{*}$ Number of cases per $100 \mathrm{PY}$.

$\mathrm{AF}$, atrial fibrillation; GI, gastrointestinal; PY, person-years; VKA, vitamin $\mathrm{K}$ antagonists.

Table 4 Incidence of hospitalisations and all-cause mortality stratified by VKA use

\begin{tabular}{|c|c|c|c|c|c|c|c|c|c|c|c|c|c|c|c|}
\hline \multirow[b]{2}{*}{ Event } & \multicolumn{3}{|l|}{ Overall } & \multicolumn{3}{|c|}{ Current exposure } & \multicolumn{3}{|c|}{ Recent exposure } & \multicolumn{3}{|c|}{ Past exposure } & \multicolumn{3}{|l|}{ No use } \\
\hline & $\begin{array}{l}\text { Number of } \\
\text { outcome } \\
\text { events }\end{array}$ & PY & $\begin{array}{l}\text { Incidence* } \\
(95 \% \mathrm{Cl})\end{array}$ & $\begin{array}{l}\text { Number of } \\
\text { outcome } \\
\text { events }\end{array}$ & PY & $\begin{array}{l}\text { Incidence } \\
(95 \% \mathrm{Cl})\end{array}$ & $\begin{array}{l}\text { Number of } \\
\text { outcome } \\
\text { events }\end{array}$ & PY & $\begin{array}{l}\text { Incidence* } \\
(95 \% \mathrm{Cl})\end{array}$ & $\begin{array}{l}\text { Number of } \\
\text { outcome } \\
\text { events }\end{array}$ & PY & $\begin{array}{l}\text { Incidence } \\
(95 \% \mathrm{Cl})\end{array}$ & $\begin{array}{l}\text { Number of } \\
\text { outcome } \\
\text { events }\end{array}$ & PY & $\begin{array}{l}\text { Incidence } \\
(95 \% \mathrm{Cl})\end{array}$ \\
\hline \multicolumn{16}{|c|}{ Hospitalisations } \\
\hline Any & 11701 & 13291 & 88.0 (86.4 to 89.6 ) & 3110 & 4601 & 67.6 (65.2 to 70.0$)$ & 599 & 788 & 76.0 (70.0 to 82.4$)$ & 836 & 1074 & 77.8 (72.7 to 83.3 ) & 7156 & 6827 & 104.8 (102.4 to 107.3 ) \\
\hline $\mathrm{AF}$ & 3962 & 24761 & $16.0(15.5$ to 16.5$)$ & 1358 & 8487 & $16.0(15.2$ to 16.9$)$ & 233 & 1610 & $14.5(12.7$ to 16.5$)$ & 215 & 2649 & 8.1 (7.1 to 9.3$)$ & 2156 & 12015 & 17.9 (17.2 to 18.7$)$ \\
\hline Mortality & 2858 & 31939 & 8.9 (8.6 to 9.3$)$ & 396 & 11663 & 3.4 (3.1 to 3.7 ) & 361 & 2359 & $15.3(13.8$ to 17.0$)$ & 440 & 3830 & 11.5 (10.4 to 12.6 ) & 1661 & 14086 & $11.8(11.2$ to 12.4$)$ \\
\hline
\end{tabular}

${ }^{*}$ Number of cases per $100 \mathrm{PY}$.

$\mathrm{AF}$, atrial fibrillation; PY, person-years; VKA, vitamin $\mathrm{K}$ antagonists. 
The strengths of the study include the large sample size of a population representative of the UK population. Although only a proportion of the eligible population could be linked to the HES/ONS data, the comparison of patient characteristics between the overall cohort of incident $\mathrm{AF}$ patients and the final study population showed no major differences (see online supplementary table S5), and thus should remain representative for the incident $\mathrm{AF}$ population in the UK. In addition, a recent comparison of patients included or not in the linkage found that there were no differences in patient characteristics. ${ }^{18}$ Linkage of data from hospital and official death certificates added valuable information and confirmed data validity. Another important strength is the up-to-date data. The timing of the data collection (2005-2010) allows for the most appropriate understanding of event rates compared to older datasets, for example, from the 1990s, especially in the context of changing concomitant treatments of comorbidities (eg, intensity of use of antihypertensives, lipid-lowering drugs and newer antiarrhythmic drugs) and immediately before NOACs were launched. ${ }^{19}$ This data will help to set future data on NOACs into perspective. With the introduction of NOACs into the market, a new era has started, that will change the disease and treatment landscape and its impact on routine clinical practice needs to be established using such studies. In addition, incident cohorts are the most valid basis for incidence estimates. $^{20}$ For appropriate thromboprophylaxis, it is crucial to assess stroke and bleeding risk using current risk stratification scores. ${ }^{21}$ In addition, information of our study about current incidence rates of common comorbidities and outcomes in the AF patient population will help to guide clinical management decisions of patients with $\mathrm{AF}$ and put further data into perspective.

Nonetheless, there are limitations to this study. We did not have information on the diagnostic criteria used for the AF diagnosis, such as ECG, and underdiagnosis of AF is a current public health problem. However, a previous CPRD study - although inclusion criteria of patients with $\mathrm{AF}$ differ slightly compared to our study-reported a high level of validity in the recording of AF by GPs. ${ }^{22}$ The procedures used to diagnose strokes and clinical presentation of stroke cases are not recorded in CPRD. In our main analysis, only hospitalised outcomes are included, likely leading to lower incidence rates as less severe outcomes will not lead to hospitalisation (eg, minor bleedings or transient ischaemic attack). This is also shown in our sensitivity analysis of cardiovascular outcomes. Furthermore, drug exposure was based on prescriptions and/or INR measurements and assumptions on dosages had to be made. We cannot exclude that patients may be supplied with VKAs for more than a month's needs, and that some patients currently taking VKAs were misclassified under recent exposure. No over-the-counter medications such as aspirin could be considered. Our analyses on haemorrhagic stroke and intracranial haemorrhage are based on low numbers of events, and no firm conclusions can be drawn. Only crude estimates were estimated which do not allow any assessment of causal relationships between exposures and outcomes. Finally, this is an observational study and patients were not randomised to a particular treatment. Changes in the exposure to VKAs are expected to be influenced by confounding factors. Stopping of preventive treatments such as VKA treatment can occur in patients with worsening of the health status. ${ }^{23-25}$ These patients would provide data to the 'recent exposure' category, and thus might increase the incidence of outcome events.

Direct comparisons of incidence rates between CPRD data and randomised controlled trials (RCTs) have limitations due to differences in inclusion/exclusion criteria and outcome definitions and adjudication. However, for outcomes that are more consistently defined (such as mortality), a comparison of incidence rates in RCTs and actual clinical practice may show the external validity and representativeness of the RCT evidence. It has been proposed that mortality rates in RCTs provide an important guide to the representativeness of a RCT. $^{26}$ In such RCTs, mortality rates were mainly between 3 and 5/100 PY. ${ }^{27}{ }^{28}$ In this CPRD study, the mortality rate was well within this range for current VKA use, but higher for recent, past and non-use. Our study shows major differences when stratifying patient groups into current, recent, past and no VKA use. Patients who recently stopped VKA treatment show the highest mortality rate, which might be related to the circumstance that effective drugs are likely not used by patients nearing death, due to selective non-prescription by physicians or non-adherence by patients. ${ }^{23}$

In conclusion, this study provides a comprehensive description of incident $\mathrm{AF}$ patients and estimates of the incidence of vascular and other outcomes in patients with AF in a GPs' database linked to hospital data from the years immediately before new oral anticoagulants were introduced.

Author affiliations

${ }^{1}$ Clinical Practice Research Datalink, London, UK

${ }^{2}$ Utrecht Institute for Pharmaceutical Sciences, Utrecht University, Utrecht, The Netherlands

${ }^{3}$ Corp Department Global Epidemiology, Boehringer Ingelheim GmbH, Ingelheim am Rhein, Germany

${ }^{4}$ Boehringer Ingelheim Pharma GmbH \& Co KG, Ingelheim am Rhein, Germany

${ }^{5}$ Center for Thrombosis and Hemostasis, Johannes Gutenberg University, Medical Center, Mainz, Germany

${ }^{6}$ Hannover Medical School, Hannover, Germany

Acknowledgements The authors thank Tim Waterboer and Kristina Zint for their input and revision of the article.

Contributors AMG, TPVS, TM-T, DA, DBB and AC participated in the study design and data analysis. The first draft of the manuscript was written by DA, $\mathrm{DBB}$ and $\mathrm{AC}$. All authors interpreted the results, revised the report, commented on the manuscript and approved the final version.

Funding The study was funded by Boehringer Ingelheim International $\mathrm{GmbH}$. Clinical Practice Research Datalink (CPRD) is owned by the UK Department of Health and operates within the Medicines and Healthcare products Regulatory 
Agency (MHRA). CPRD receives funding from various regulatory authorities, universities, contract research organisations and pharmaceutical companies. The department of Pharmacoepidemiology \& Pharmacotherapy, Utrecht Institute for Pharmaceutical Sciences has received unrestricted funding for pharmacoepidemiological research from GlaxoSmithKline, Novo Nordisk, the private-public funded Top Institute Pharma (http://www.tipharma.nl, includes cofunding from universities, government and industry), the Dutch Medicines Evaluation Board and the Dutch Ministry of Health.

Competing interests $\mathrm{DA}, \mathrm{DBB}, \mathrm{AC}$ and NS are employees of Boehringer-Ingelheim, the manufacturer of dabigatran etexilate. CPRD received funding from Boehringer Ingelheim $\mathrm{GmbH}$ for the conduct of this study.

Ethics approval The CPRD has been granted Multiple Research Ethics Committee (MREC) approval (05/MRE04/87) to undertake purely observational studies, with external data linkages including HES and ONS mortality data. The work of CPRD is also covered by NIGB-ECC approval ECC 5-05 (a) 2012. This study was approved by the Independent Scientific Advisory Committee for MHRA database research (ISAC) under protocol numbers 10/018 and 12/050.

Provenance and peer review Not commissioned; externally peer reviewed.

Data sharing statement Read and ICD-10 codes, and further details on methodology are available from the corresponding author.

Open Access This is an Open Access article distributed in accordance with the Creative Commons Attribution Non Commercial (CC BY-NC 3.0) license which permits others to distribute, remix, adapt, build upon this work noncommercially, and license their derivative works on different terms, provided the original work is properly cited and the use is non-commercial. See: http:// creativecommons.org/licenses/by-nc/3.0/

\section{REFERENCES}

1. Camm AJ, Kirchhof $P$ Lip GY, et al. Guidelines for the management of atrial fibrillation: the Task Force for the Management of Atrial Fibrillation of the European Society of Cardiology (ESC): developed with the special contribution of the European Heart Rhythm Association (EHRA), endorsed by the European Association for Cardio-Thoracic Surgery (EACTS). Eur Heart J 2010;31:2369-429.

2. Connolly SJ, Pogue J, Eikelboom J, et al. ACTIVE W investigators benefit of oral anticoagulant over antiplatelet therapy in atrial fibrillation depends on the quality of international normalized ratio control achieved by centers and countries as measured by time in therapeutic range. Circulation 2008;118:2029-37.

3. Connolly SJ, Ezekowitz MD, Yusuf S, et al. Dabigatran versus warfarin in patients with atrial fibrillation. N Engl J Med2009;361:1139-51.

4. Jabre $\mathrm{P}$, Jouven $\mathrm{X}$, Adnet $\mathrm{F}$, et al. Atrial fibrillation and death after myocardial infarction: a community study. Circulation 2011;123:2094-100.

5. Williams T, van staa T, Puri S, et al. Recent advances in the utility and use of the General Practice Research Database as an example of a UK Primary Care Data resource. Ther Adv Drug Saf 2012;3:89-99.

6. Herrett E, Thomas SL, Schoonen WM, et al. Validation and validity of diagnoses in the General Practice Research Database: a systematic review. Br J Clin Pharmacol 2010;69:4-14.

7. Gage BF, Waterman AD, Shannon W, et al. Validation of clinical classification schemes for predicting stroke: results from the Nationa Registry of Atrial Fibrillation. JAMA 2001;285:2864-70.

8. Lane DA, Lip GYH. Use of the CHA2DS2-VASc and HAS-BLED scores to aid decision making for thromboprophylaxis in nonvalvular atrial fibrillation. Circulation 2012:126:860-5.
9. Rietbrock S, Heeley E, Plumb J, et al. Chronic atrial fibrillation: incidence, prevalence, and prediction of stroke using the congestive heart failure, hypertension, age $>75$, diabetes mellitus, and prior stroke or transient ischemic attack (CHADS2) risk stratification scheme. Am Heart J 2008;156:57-64.

10. Lewis JD, Brensinger C. Agreement between GPRD smoking data: a survey of general practitioners and a population-based survey. Pharmacoepidemiol Drug Saf 2004;13:437-41.

11. Hansen ML, Sørensen R, Clausen MT, et al. Risk of bleeding with single, dual, or triple therapy with warfarin, aspirin, and clopidogrel in patients with atrial fibrillation. Arch Intern Med 2010;170:1433-41.

12. Olesen JB, Lip GY, Lindhardsen J, et al. Risks of thromboembolism and bleeding with thromboprophylaxis in patients with atrial fibrillation: a net clinical benefit analysis using a 'real world' nationwide cohort study. Thromb Haemost 2011;106:739-49.

13. Frost L, Andersen LV, Vestergaard $P$, et al. Trends in risk of stroke in patients with a hospital diagnosis of nonvalvular atrial fibrillation: national cohort study in Denmark, 1980-2002. Neuroepidemiology 2006;26:212-19.

14. Friberg L, Hammar N, Rosenqvist M. Stroke in paroxysmal atrial fibrillation: report from the Stockholm Cohort of Atrial Fibrillation. Eur Heart J 2010;31:967-75.

15. Go AS, Hylek EM, Chang Y, et al. Anticoagulation therapy for stroke prevention in atrial fibrillation: how well do randomized trials translate into clinical practice? JAMA 2003;290:2685-92.

16. Ruigomez A, Johansson S, Wallander MA, et al. Risk of cardiovascular and cerebrovascular events after atrial fibrillation diagnosis. Int J Cardiol 2009;136:186-92.

17. Fang MC, Go AS, Chang $Y$, et al. Death and disability from warfarin-associated intracranial and extracranial hemorrhages. Am J Med 2007;120:700-5.

18. Gallagher AM, Puri S, van Staa TP. Linkage of the General Practice Research Database (GPRD) with Other Data Sources [528]. Poster presentation at 27th International Conference of Pharmacoepidemiology, August 16th 2011, Chicago, IL, USA

19. Parkinson J, Davis S, van Staa TP. The General Practice Research (GPRD) Database: now and the future. In: Mann R. Pharmacovigilance editor. 2nd edn. John Wiley \& Sons 2007:341-8.

20. Schneeweiss S. A basic study design for expedited safety signal evaluation based on electronic healthcare data. Pharmacoepidemiol Drug Saf 2010;19:858-68.

21. Lip GY. Stroke and bleeding risk assessment in atrial fibrillation: when, how, and why? Eur Heart J 2013;34:1041-9.

22. Ruigómez A, Johansson S, Wallander M-A, et al. Incidence of chronic atrial fibrillation in general practice and its treatment pattern. $J$ Clin Epidemiol 2002;55:358-63.

23. Glynn RJ, Knight EL, Levin R, et al. Paradoxical relations of drug treatment with mortality in older persons. Epidemiology 2001;12:682-9.

24. Redelmeier DA, Tan SH, Booth GL. The treatment of unrelated disorders in patients with chronic medical diseases. $N$ Engl J Med 1998;338:1516-20.

25. Stürmer T, Rothman KJ, Avorn J, et al. Treatment effects in the presence of unmeasured confounding: dealing with observations in the tails of the propensity score distribution-a simulation study. $A m$ $J$ Epidemiol 2010;172:843-54.

26. Silberman G, Droitcour JA, Scullin EW. Cross design synthesis: a new strategy for medical effectiveness research. Darby, USA: Diane Publishing Co, 1992.

27. Patel MR, Mahaffey KW, Garg J, et al. Rivaroxaban versus warfarin in nonvalvular atrial fibrillation. $N$ Engl J Med 2011;365:883-91.

28. Granger $\mathrm{CB}$, Alexander $\mathrm{JH}$, McMurray JJ, et al. Apixaban versus warfarin in patients with atrial fibrillation. $N$ Engl J Med 2011;365:981-92. 